\title{
The Study of Patients Mental State by Color Diagnostic Method
}

\author{
Kristina Karen Vardanyan, Gayane Albert Ghazaryan \\ Yerevan State Medical University, Yerevan, Republic of Armenia
}

\begin{abstract}
The aim of the presented research was to study the effect of hospital greenery on the psycho-emotional status of children receiving long-term inpatient care. Since ancient times people had been using natural resources to shake off psycho-emotional tension; visual and tactile contacts with flora help people to realize their place in the world, relieve psycho-emotional tension, and enhance healing process. A "green room” with specially selected houseplants was created in the Pediatric Endocrinology Department of "Mouratsan” Hospital in Yerevan. The psycho-emotional status of two groups of randomly selected hospitalized children aged 6-13 and receiving standard drug and a 10-day art-therapy treatment were studied. The art-therapy of the children of the experimental group $(\mathrm{G} 1, N=21)$ was conducted in the "green room" under the guidance of a specially instructed healthcare worker. The psycho-emotional status of two groups of children from the same department was tested using the WLF ("Wonderland of feelings”) method by Zinkevich-Yevstigneyeva T. D. and colleagues. The comparison of the test results of the experimental and control groups of children demonstrated statistically significant difference: Interaction of all colors was almost twice higher in experimental group. The second parameter was the adequacy of feelings to the choice of colors that did not show significant difference in two groups. The third measurement regarded the degree of filling a man's silhouette with colors that was significantly improved in the experimental group that could be interpreted as getting to know and accept the body. Creating green comfortable environment in the hospital relieves tension, alleviates the traumatic effect of the hospital on children's psyche, and can eventually improve the treatment outcomes.
\end{abstract}

Keywords: phytodesign of hospitals, psycho-emotional comfort, art-therapy, ousting of color, emotion and colors

\section{Introduction}

Provision of healthcare facilities with comfortable environment is of the highest importance in hospital management. Human emotional feelings are an important factor influencing on the recovery process. However, the problems of patient's psycho-emotional comfort as an important psycho-hygienic factor in healthcare facilities and in providing a medical aid are not considered properly.

To shake off psycho-emotional tension people have been using natural resources for centuries. Visual and tactile contacts with flora help people to realize their places in the world due to a reflection process, directed both to themselves and the surrounding plants (Baran \& Nikiforov, 2008).

Contemporary medical investigations prove that contact with plants has a favorable influence on the nervous system, decreases tiredness, restores working efficiency, etc. (William \& Darlen, 1976; Ulrih, 1984;

Kristina Karen Vardanyan, Ph.D., associate professor, Department of Hygiene and Ecology, Chief of Landscape and Gardening Department, Yerevan State Medical University.

Gayane Albert Ghazaryan, Ph.D., associate professor, Department of Clinical Psychology, Yerevan State Medical University. 
Virginia, Lohr, Caroline, Pearson-Mims, \& Georgia, 1996; Dijkstra, Pieters, \& Pruyn, 2008; Bjorn \& Grete, 2009; Grace, 2009).

In order to study the influence of phyto-design on psycho-emotional status of patients, we have implemented the WLF (Wonderland of feelings) method by Zinkevich-Yevstigneyeva (2006). The selection of this method is justified by the fact that it gives a chance to reveal the complete picture of the psycho-emotional status of the person undergoing the investigation. The bases of emotion and color entailment were demonstrated in earlier studies (Yanshin, 1996; Dragunskiy, 2000). Thus, according to Bazima, emotions and color have some common conformity to natural laws: First, emotions and colors are "interlaced" on a very deep base and present themselves as an objective realization of emotions; and secondly, a definite emotion is "allotted" to a certain color at a rather rough degree (Bazima \& Kutko, 1997; Adashinskaya, 2003; Adashinskaya, Yenikopolov, \& Meyzerov, 2005; Bazima, 2007; Selchonok, 2007).

A mentally healthy person beginning from the age of $3-4$, realizes the emotional content of the main colors, alongside with the development of the ability to verbalize impressions, and is able to differentiate colors by the emotional sign (Bazima, 2001).

Comprehension of the full spectrum of colors is the base of harmonic vision, e.g., in Japan children's education starts with identifying the absence of certain colors in pictures and then the comprehension of all the known colors is achieved. "Harmony in color-harmony in the soul-harmony in life" is one of the utmost important objectives of a Japanese teacher (Orekhova, 2002).

\section{Material and Methods}

For conducting this investigation, we have created a green room in the University Clinic "Mouratsan" implementing medical phytodesign technologies (Kazarinova \& Tkachenko, 2004; Vardanyan \& Hayrapetyan, 2009). To fulfill the goal we have examined two children's groups, aged from six to 13, 21 in each group who were receiving treatment in "Mouratsan" University Clinic. Alongside with standard drug treatment protocols, a 10-day art therapy was conducted by the clinic's psychologist in both groups.

The first group (experimental) G1 included children who have received art therapy by the above-mentioned method in the green room. Every day the patients spent an hour there, having the chance for visual and physical contact with the house plants. The children had the right to choose a blossoming "green" friend according to their own color preference, those who were interested were taking care after the plants (see Figure 1).

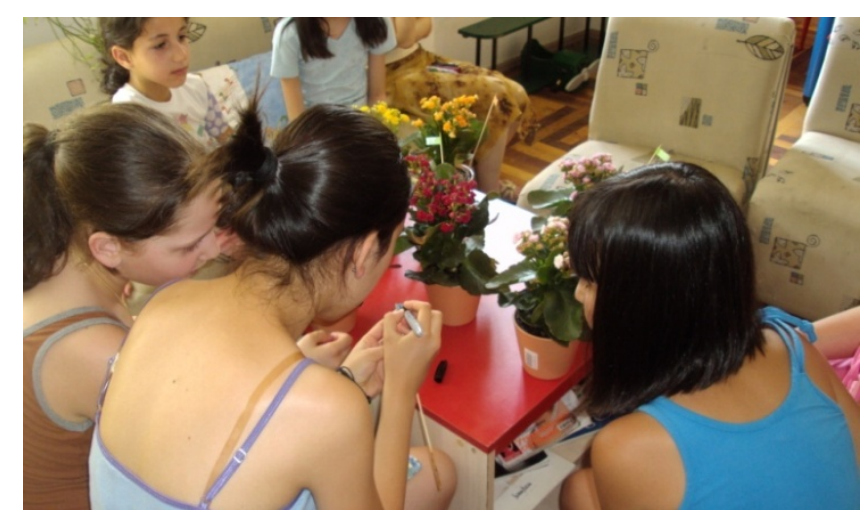

Figure 1. The process of therapy in G1 group. 


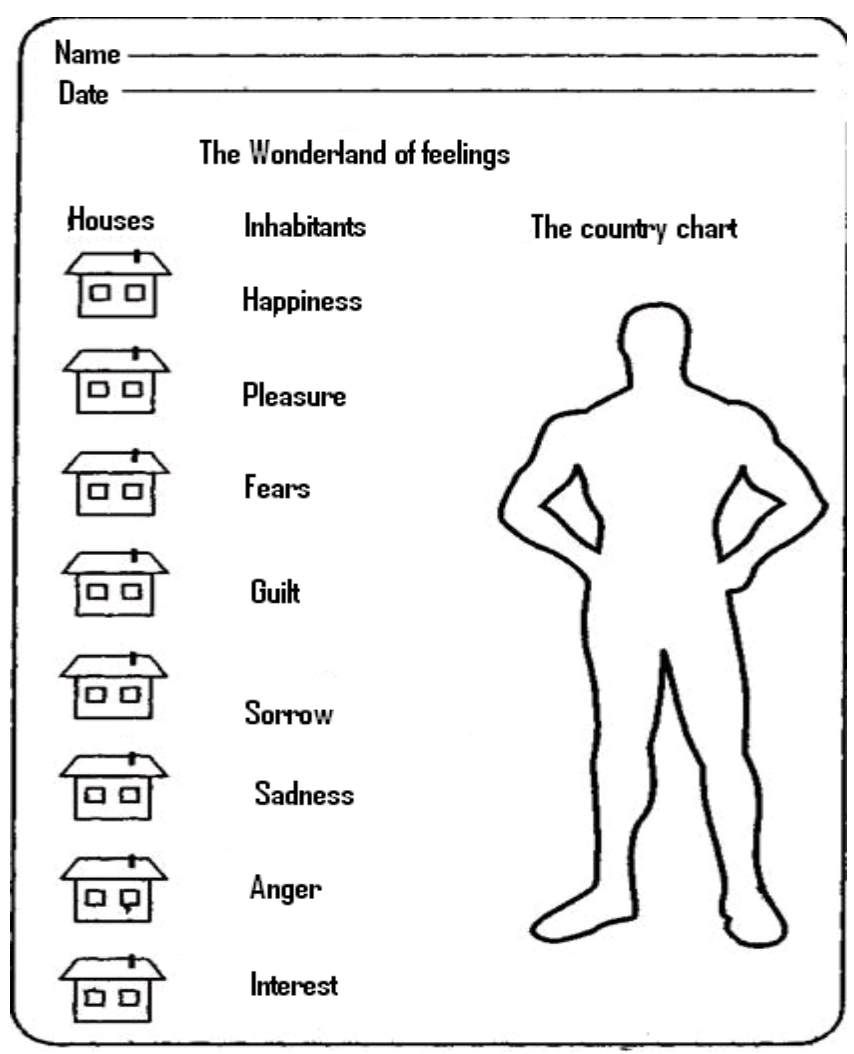

Figure 2. The blank forms used in the WLF method.

The second group (control) G2, received art therapy by the same method but without visiting the green room.

On the first day of investigating the children from both groups underwent a test by the WLF method. The child was given colorful pencils (red, yellow, blue, green, violet, brown, grey, and black) and a blank paper where the main emotions were mentioned (happiness, pleasure, fear, guilt, sorrow, offence, fury, and interest) in small houses and human silhouettes (see Figure 2).

Diagnosis was made according to the following parameters: (1) whether all the colors were used; (2) if the choice of colors was adequate to painting the emotions in the houses; and (3) color distribution in the human silhouette.

The silhouette is symbolically divided into five zones:

(1) The head and the neck symbolize mental activity;

(2) The trunk up to the waist-emotional;

(3) The hand up to the shoulder-communicative;

(4) Pelvic-femoral area—sexual and creative feelings;

(5) Legs — sense of confidence, as well as the possibility for "earthing” negative feelings.

On the 10th day, the second testing was conducted in the both groups. The results of examining the psycho-emotional status of the experimental group children were compared with the results of the control one.

For statistic analysis was used, the packets of Excel 2007 and XLSTAT (XLSTAT complete analysis and statistics add-in for MS Excel) 2009 programs. We have compared the results of the two groups on the first and 10th days of the investigation by using Mann-Witny's criteria. 


\section{Results and Discussion}

The results of analysis by color ousting percentage have revealed statistically significant difference between the two groups on the 10th day of the investigation, when painting the houses $(p=0.04)$ as well as the human silhouette $(p=0.002)$ whereas before the investigation there was not any difference either in painting emotions $(p=0.83)$ or in the human silhouettes $(p=0.69)$.

The analysis of the obtained data on color ousting (Figures 3-6) both in emotions and human silhouettes has shown the greatest in the two groups for the ousting of the black color.

By its psychological index the black color (data presented by column 7 in the diagram) characterizes the attitude to the absolute (authority, fate, death), symbolizes refusal, full renunciation, or rejection. Ousting of the black color is explained by fear for thinking about their state, unwillingness to realize the real state of their health (Dragunskiy, 2000; Selchonok, 2007). This position excludes the patient's work on improving his/her state during the course of treatment. On the 10th day of the investigation in the G1 group the percentage of color ousting in emotions did not change, in the silhouette decreased 1.5 times. In the control group a decrease by 5.9 times was noted in emotions and 1.2 times in silhouettes.

The next most significant difference was reported for the ousting of the brown color (No. 6 in the diagram). In the color diagnostics it characterizes the physical requirements of the organism. Not using that color characterizes ousting of fear, tiredness, overexertion, which are observed in the children on admission to hospital. As a result of therapy, significant changes were observed in emotions (3.8 times) and in human silhouette (1.9 times) in the experimental group, whereas in the control group no chances were observed in emotions but a decrease by 1.3 times was observed in the silhouette.

The next come the colors grey, blue, yellow, and violet (14\% each).

In psychology the grey color (No. 0 in the diagram) characterizes attitude to the collective body, integration. It is also separating, shutting off, releasing from the duties, hiding from external causes and effects. Grey ousting can speak about being isolated and estrangement. Reason for it can be the child's fear that he/she is not like others, that other children's attitude to him/her can get worse because of his/her disease. In the two groups, there observed an increase twice in the experimental group emotions, 1.3 times in the control group, in the human silhouette in group G1 a decrease by1.2 times, whereas in the control group an increase by 1.2 times.

In color diagnostics the color blue (No. 1 in the diagram) characterizes tendency to rest, intensive requirement for pleasant contact and satisfaction, tendency to harmony.

Quite a good result is obtained in the experimental group where the ousting percentage decreased in emotions up to zero, and 4.8 times in silhouettes, i.e., after the contact with house plants all the children became quiet and confident, whereas in the control group emotions increased 1.9 times, but no change was seen in the silhouette.

The yellow color (No. 4 in the diagram) characterizes optimism, good mood, high-self-evaluation, tranquility, and adaptation. Exception of this color from the whole spectrum of colors in children speaks about their decreased mood, they do not allow themselves to believe themselves, become happy, and avoid being responsible for their state. In the experimental group color ousting percentage in emotions decreased 2.8 times, increased 1.4 times in the silhouette, whereas in the control group, just on the contrary, an increase by 2.4 times was observed both in the emotions and human silhouette.

The violet color (No. 5 in the diagram) characterizes fantasy, sensitivity, and esthetic aspiration. Presence 
of fantasy helps the patients to compose a full "internal picture of the disease". According to Lurina (1977), IPD (internal picture of the disease) is all that the patients experience and suffer, whatever they feel, not only local (painful), but also general-their being well, about their illness and its causes. It is also everything connected with their visit to the doctor, their emotions, affects, psychic feelings, and traumas (Luria, 1977). In case of violet color ousting the patient loses the ability to fantasize, imagine, and compose a full IPD. Inhibition of the necessity to fantasize disturbs the patient to compose the picture of convalescence. In the experimental group the percentage of this color ousting decreased 2.8 times in emotions, in the human silhouette it was equal to 0, i.e., all the children of the experimental group have restored their abilities to fantasize and esthetic tendency after the contact with the house plants, in the control group, on the contrary, an increase of color ousting percentage by 2.4 times is observed both in the emotions and human silhouette.

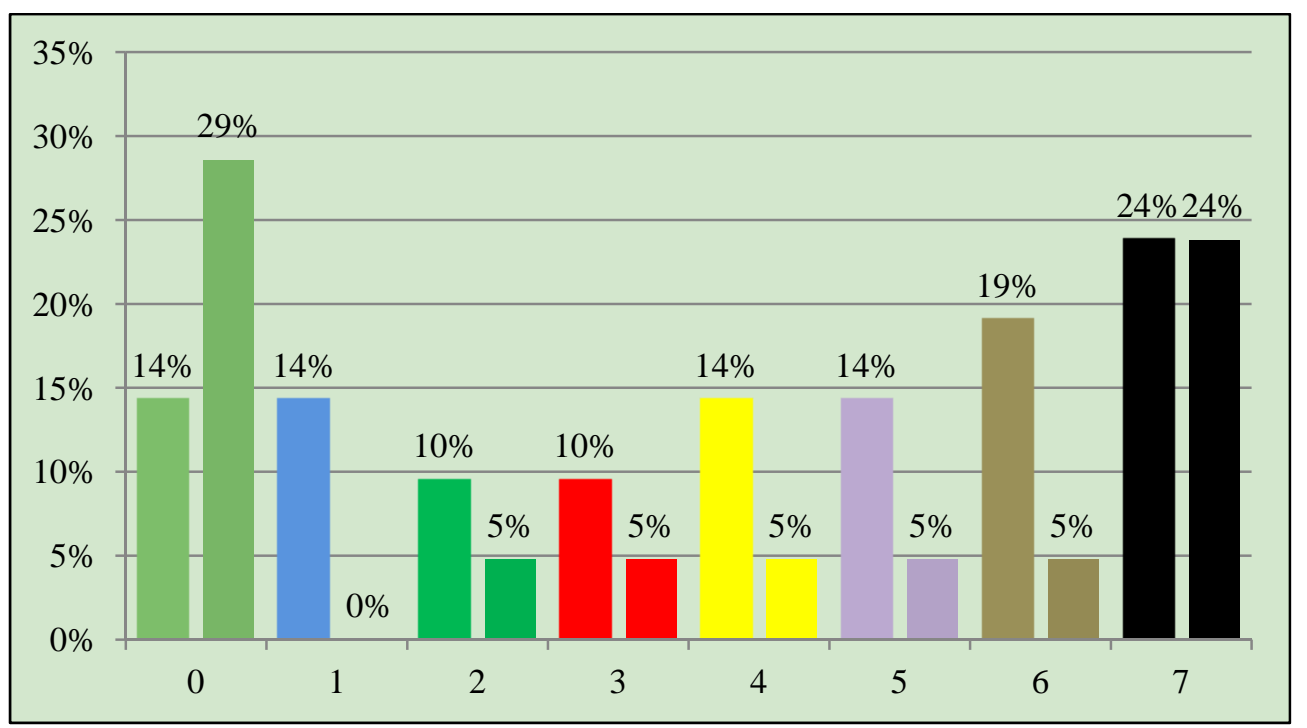

Figure 3. Color ousting in the group of children visiting the green room, before and after the course (emotions).

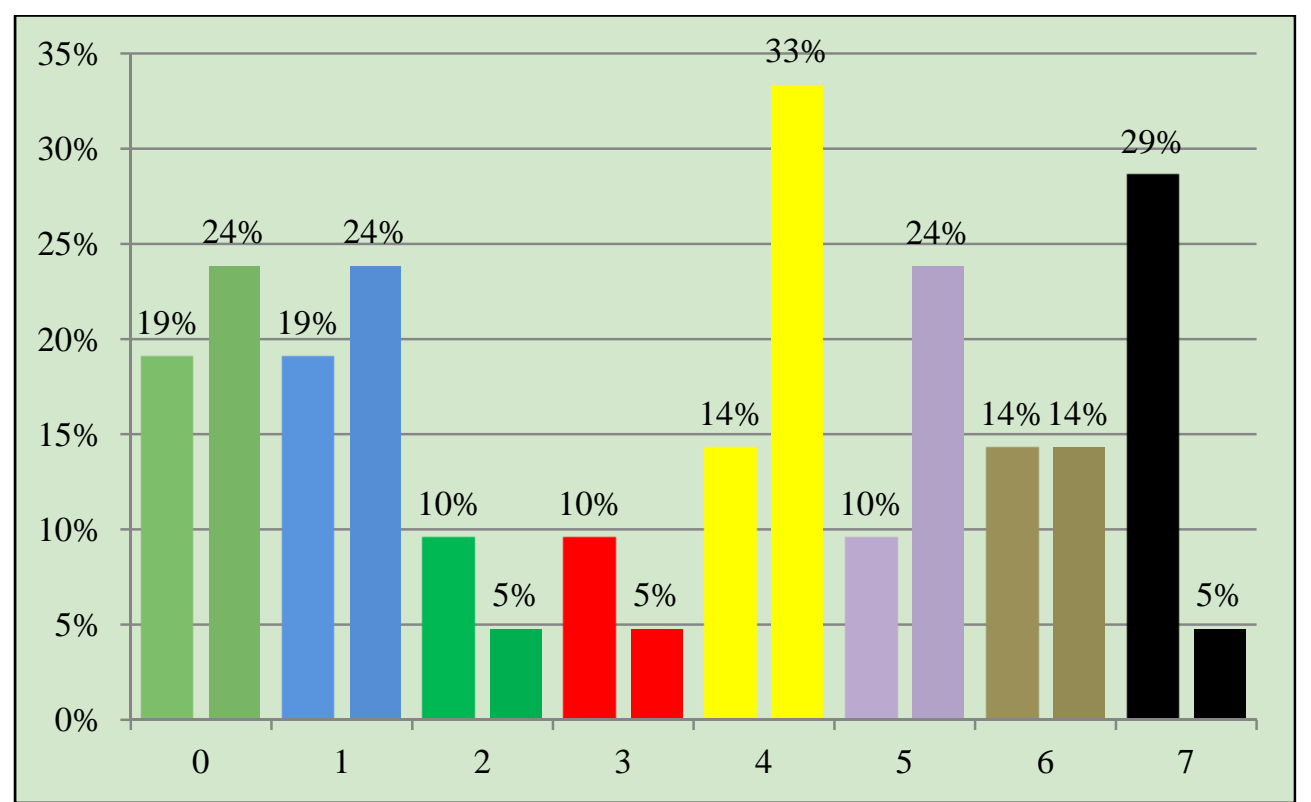

Figure 4. Color ousting in the group of children not visiting the green room, before and after the course (emotions). 


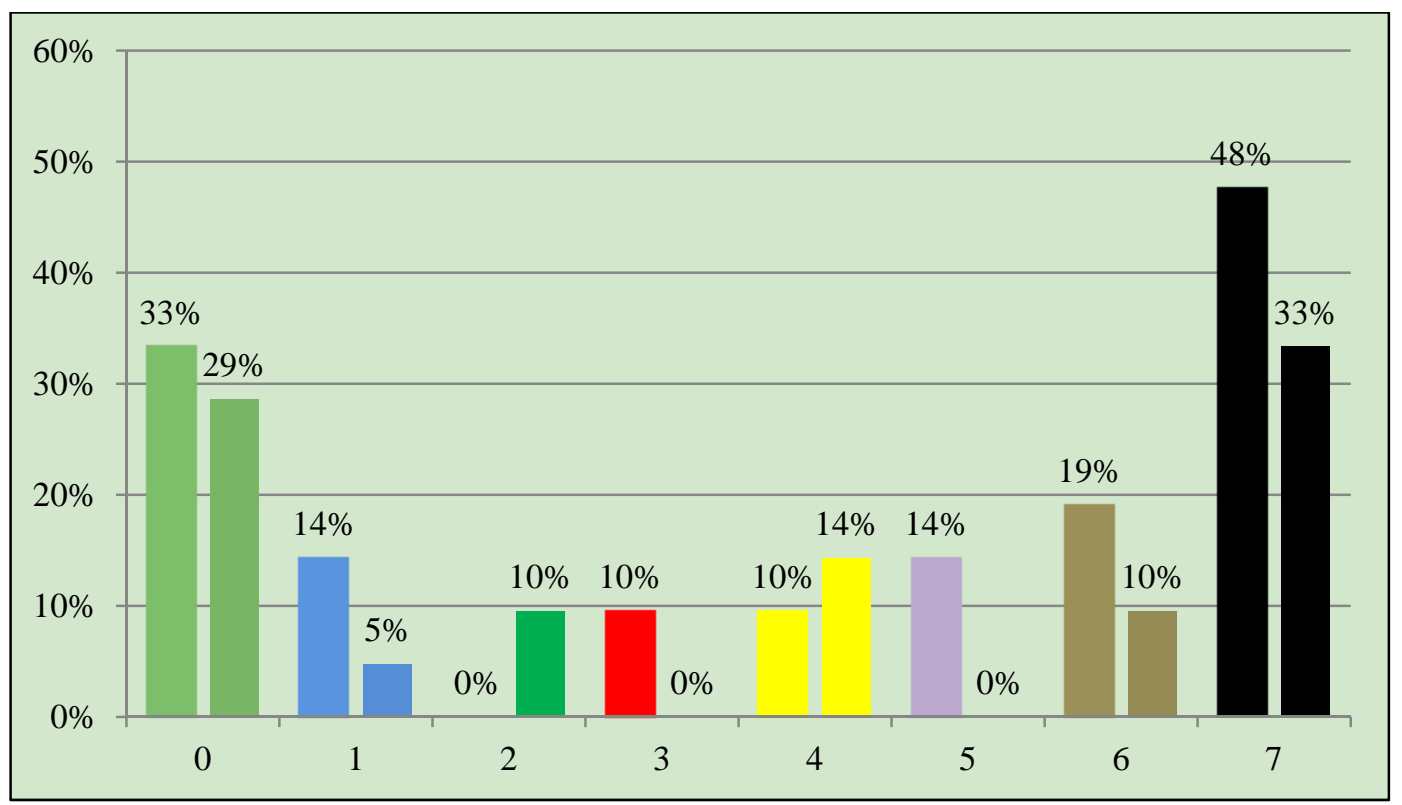

Figure 5. Color ousting in the group of children visiting the green room, before and after the course (human silhouette).

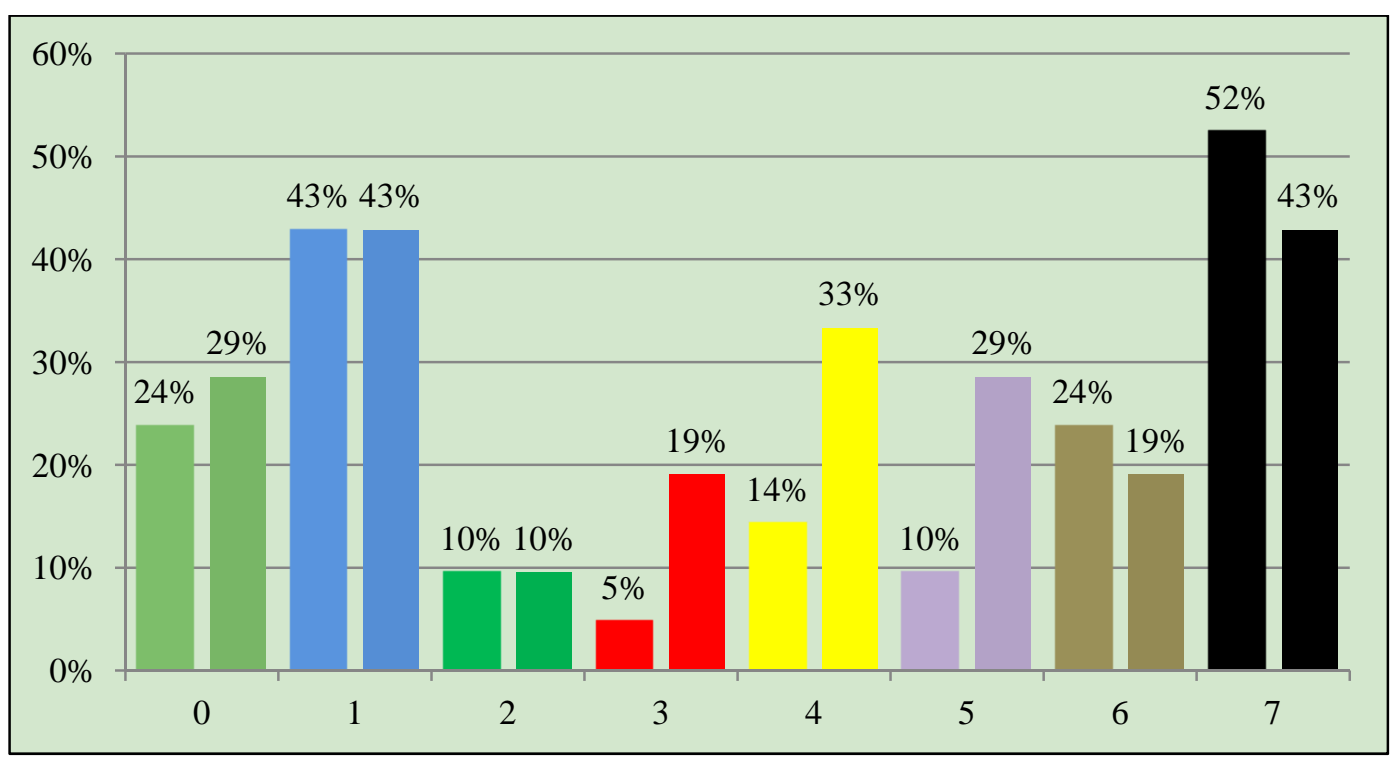

Figure 6. Color ousting in the group of children not visiting the green room, before and after the course (human silhouette).

Ousting of the green and red-orange colors is in the last place composing $10 \%$ each.

The characteristics of the green color (No. 2 in the diagram) are: self-affirmation, confidence, vanity, persistence, and tension of the willpower. Ousting of these characteristic features in children allows us to consider them passive. They have low level claims, cannot believe in themselves and their power. During the treating process the percentage of green color ousting in emotions decrease twice in the both groups, in the experimental group human silhouette it decreased up to zero, i.e., all the children in the experimental group restored the capacity for fantasy and esthetic tendency, no changes was observed in the control group.

In the end, red-orange color (No. 3 in the diagram) characterizes tendency to bright emotions, participation 
and high activity. In case of this color ousting hyper irritation, sensation of weakness, fatigue, and sense of helplessness can be observed in children. The rate of red-orange color ousting in emotions decreased twice in the two groups, in the experimental group human silhouette it decreased up to zero, in the control one, on the contrary, it increased 3.8 times. By the end of the treatment all the children in the first group begin to display tendency to bright emotions, active participation, and high activity, which cannot be seen in the control group children.

Thus, we can see significant results in the experimental group. A decrease in color ousting, tending to zero, is observed in the experimental group (for the blue, red, and violet), whereas in the control group such results had never been observed, which demonstrates the usefulness of using phyto-design for the hospitalized children's rehabilitation. The psycho-emotional state of the experimental group of children improved quicker than in the control group who will need longer rehabilitation work with the psychologist.

\section{Conclusions}

Psycho-emotional state of the first group of children differs greatly from that of the control group. An important conclusion is that in the result of "green room" therapy for the hospitalized children strengthened the belief in recovery and inner abilities to overcome the disease, increased optimism, improved mood, and self-esteem.

Creating green comfortable environment in the hospital promotes the relief off tension, relieves the traumatic effect of the hospital on children's psyche, and can ease the process of children's adaptation to the hospital. Eventually, it can have a significant influence on the treatment outcomes.

\section{References}

Adashinskaya, G. A. (2003). Color choice as a method for evaluating the pain. Pain, 3, 30-33.

Adashinskaya, G. A., Yenikopolov, S. N., \& Meyzerov, Ye. Ye. (2005). Pain and color. Psychological Magazin, 26(3), 74-80.

Baran, V. E., \& Nikiforov, Yu. V. (2008). Landscape-therapy as one of the most effective methods of medico-social rehabilitation of patients with psychic disorders. Journal of Psychiatry and Medical Psychology, 1(18), 90-93.

Bazima, B. A. (2001). Color and psyche (p. 172). Khark State Academy of Culture-X, KhDAC.

Bazima, B. A. (2007). Psychology of color; theory and practice CP. In K. V. Selchonok (2005), Latest color-psychology (p. 672). Minsk, Harvest.

Bazima, B. A., \& Kutko, E. E. (1997). Color preferences of adolescents with character accentuations. Journal of Neurology and Psychiatry After Korsakov S.S., 97(1), 24-28.

Bjorn, G., \& Grete, G. P. B. (2009). Does visual contact with nature impact on health and well-being? International Journal of Environmental Research and Public Health, 6, 2332-2343.

Dijkstra, K., Pieters, M. E., \& Pruyn, A. (2008). Stress-Reducing effects of indoor plants in the built healthcare environment, the mediating role of perceived attractiveness. Preventive Medicine, 47(3), 279-283.

Dragunskiy, V. V. (2000). Color personal test (p. 448). In Practical handout. Minsk, Harvest.

Grace, A. K. (2009). Does a view of nature promote relief from acute pain? Journal of Holistic Nursing, 27(3), 159-166.

Kazarinova, N. V., \& Tkachenko, K. G. (2004). Emotional esthetic peculiarities of medical phytodesign. Resort Bulletin, 3(24), 38-43.

Luria, R. A. (1977). Internal picture of the disease and iatrogenic diseases (4th ed., p. 111). Meditsina.

Orekhova, O. A. (2002). Color diagnostics of child's emotions (p. 117). Speech.

Selchonok, K. V. (2007). Latest color psychology (p. 672). Minsk, Harvest.

Ulrih, R. S. (1984). View through a window may influence recovery from surgery. Science, 4647, 420-421.

Vardanyan, K. K., \& Hayrapetyan, A. K. (2009). Significance of medical phytodesign for sanation of air environment of medical-preventive institutions. MANEB, 14(1), 64-70. 
Virginia, I., Lohr, Caroline, H., Pearson-Mims, \& Georgia, K. (1996). Goodwin interior plant may improve productivity and reduce stress in a windowless environment. Journal of Environmental Horticulture, 14(2), 97-100.

William, A. R., \& Darlen, A. (1976). Stieber Stieber plant play therapy: Growth throut growth. Journal of Pediatric Psychology, $1(4), 18-20$.

Yanshin, P. V. (1996). Emotional color: Emotional component in the psychological structure of color (p. 218). Samara, Sam SPU.

Zinkevich-Yevstigneyeva, T. D. (2006). Training by tale therapy (p. 176). Speech. 